\title{
DEUDAS Y PRÉSTAMOS: LA CRISIS DEL CRÉDITO PÚBLICO EN NUEVA ESPAÑA DURANTE LA GUERRA DE INDEPENDENCIA (1810-1821)*
}

\section{DEBTS AND LOANS: THE CRISIS OF PUBLIC CREDIT IN NEW SPAIN DURING THE INDEPENDENCE WAR} (1810-1821)

\author{
Ernest Sánchez Santiró \\ Instituto de Investigaciones Dr. José María Luis Mora, Ciudad de México, México, \\ esanchez@mora.edu.mx
}

\begin{abstract}
Resumen. El presente trabajo reconstruye las definiciones y caracterizaciones empleadas por los ministros de las oficinas del erario al tratar sobre la deuda pública. Asimismo, estima su monto y composición a partir de un espacio institucional específico, la Tesorería General del fisco novohispano, en tanto que fue su principal oficina. Finalmente, el trabajo se adentra en la temática del servicio de la deuda, partiendo del supuesto de que el pago de intereses y el cumplimiento en los plazos de amortización de capitales son criterios adecuados para la periodización del estado de salud financiera del erario novohispano durante la crítica década de 1810 .
\end{abstract}

Palabras clave: deuda pública; crisis; Nueva España; guerra de Independencia; Real Hacienda; Hacienda pública.

Abstract. The work reconstructs the definitions and characterizations employed by the ministers of the Treasury offices to deal with the public debt; also estimated its amount and composition from a specific institutional space, the General Treasury of New Spain, as long as it was the main office of fiscal administration. Finally, the paper explores the theme of debt service, assuming that interest payment and compliance in the repayment of capital are appropriate criteria for the periodization of the financial health of the Novohispano Treasury during the critic decade of 1810s.

Key words: public debt; crisis; New Spain; independence war; royal treasury; public treasury.

Fecha de recepción: 19 de marzo de 2015. Fecha de aceptación: 18 de mayo de 2015.

* Este trabajo ha recibido el apoyo del Consejo Nacional de Ciencia y Tecnología (Proyecto núm. 153670).

Am. Lat. Hist. Econ., mayo-agosto, 2016, pp. 36-63 | DOI: 10.18232/alhe.v23i2.708 
El dinero es el nervio de la guerra; el crédito es el manantial del dinero

Duque de Almodóvar (1786)

\section{INTRODUCCIÓN}

$\mathrm{E}^{1}$ 1 deterioro de las finanzas públicas de Nueva España durante la guerra de Independencia cuenta con una larga tradición historiográfica (Anna, 1981; Bazant, 1968; Flores, 1969b; Hamnett, 1978; Tenenbaum 1985). En este contexto, y por su alcance historiográfico, destaca el trabajo publicado por John Jay TePaske en 1989, en el que evidenció no sólo las penurias que padeció el erario novohispano entre 1810 y 1821, sino también la respuesta financiera que adoptaron las diversas autoridades, junto a medidas de carácter tributario y de control del gasto (TePaske, 1989, 1991). Con ello se aportó una evolución general y extensa (17911817) del monto y ritmo de contratación de la deuda reconocida por la caja matriz de México, lo que abrió la puerta para el desarrollo posterior de estudios monográficos. Fueron los casos de Josefa Vega, cuando mostró los primeros donativos y préstamos (1810-1812) demandados por el fisco regio novohispano para sostener militarmente la contrainsurgencia (Vega, 1990), los trabajos de Guillermina del Valle Pavón sobre la participación del Tribunal del Consulado de México en el otorgamiento y la intermediación financiera de préstamos al erario (Valle, 1996, 1997) o los que indicaban que en dicho periodo se produjo la "etapa culminante de la bancarrota del virreinato", en el caso de Carlos Marichal (1999, pp. 294-300).

Esta línea de especialización sobre el estudio de la deuda y, sobre todo, de los préstamos contratados por la Real Hacienda y la Hacienda pública de Nueva España durante el periodo 1810-1821 se ha diversificado notablemente. ${ }^{1}$ Muestra de ello son las investigaciones centradas, por ejemplo, en las aportaciones efectuadas o intermediadas financieramente por diversas corporaciones novohispanas, como sucedió con la Iglesia poblana (Gómez, 1995), el Tribunal del Consulado de Comerciantes de la ciudad de México (Valle, 1997, pp. 27, 471-550, 2001) o el Real Tribunal de Mine-

${ }^{1}$ Dada la temporalidad general que abarca este trabajo (1799-1821), cabe mencionar que hubo cambios en la naturaleza política del organismo encargado de la recaudación y gestión de las rentas y del ejercicio del gasto del erario novohispano, ante la aprobación de la Constitución de Cádiz de 1812. En este sentido, la Real Hacienda de Nueva España (así como el resto de erarios del Hispanus fiscus) mutó en dos momentos precisos (para el caso novohispano en 1812-1814 y 1820-1821) para convertirse, según denominaciones de la época, en la Hacienda pública o en la Hacienda nacional. Un cambio que se trasladaría al conjunto de oficinas, en especial las aduanas y las tesorerías. Aquí nos interesa destacar el cambio vivido por la Tesorería General de Ejército y Real Hacienda (o de Hacienda pública) de Nueva España, también conocida como la caja matriz. 
ría (Méndez, 2012). Destaca también su estudio contextual en el marco de la fiscalidad extraordinaria que impulsó el gobierno virreinal entre 1810 y 1816 para financiar la contrainsurgencia (Jáuregui, 1999, pp. 221-280, 329352; Sánchez, 2013b; Valle, 2013) o el rastreo del pensamiento económico en torno a la deuda pública presente en algunos de los protagonistas del periodo (Sánchez, 2014a).

A la luz de esta producción historiográfica resaltan diversos aspectos. En primer lugar, el hecho de que no contamos con una definición precisa de cómo conceptualizaba el fisco novohispano la deuda del erario. Un adeudo que iba más allá de los préstamos obtenidos de corporaciones y particulares, al englobar también un volumen importante de deuda por cuenta corriente como resultado del impago de sueldos, aprovisionamientos, pensiones, mercedes y transferencias reguladas, como sucedía con los situados ultramarinos. En segundo lugar, no disponemos de una reconstrucción del stock de deuda pública, así como de su composición, para el periodo $1810-1821{ }^{2}$ Si bien contamos con estimaciones, no siempre coincidentes, del monto de la deuda que reconocía la Tesorería General de Ejército y Real Hacienda, verdadera caja matriz de la Real Hacienda de Nueva España, se desconocen las deudas originadas en otras tesorerías, con excepción del caso yucateco (Cobá, 2014; Sánchez, 2012); un hecho fundamental, si tenemos en cuenta que la fragmentación del erario ocasionada por la guerra civil ha sido uno de los fenómenos más enfatizados por la historiografía (Anna, 1981; Jáuregui, 1999; TePaske, 1989).

Como respuesta, si bien parcial, a este estado historiográfico, nuestro estudio reconstruye las definiciones y caracterizaciones empleadas por los ministros de las oficinas del erario al tratar sobre la deuda pública; asimismo, estima su monto y composición a partir de un espacio institucional específico, la Tesorería General de Ejército y Real Hacienda o de Hacienda pública (según los momentos), en tanto fue la principal oficina del erario en Nueva España. Finalmente, el trabajo se adentra en la temática del servicio de la deuda, partiendo del supuesto de que el pago de intereses y el cumplimiento en los plazos de amortización de capitales son criterios adecuados para la periodización del estado de salud financiera del erario novohispano durante la crítica década de 1810, en el entendido de que

${ }^{2}$ La diferencia historiográfica con el grado de precisión en los montos y evolución de la deuda del fisco en el tiempo que abarca desde la guerra contra Gran Bretaña (1779-1783) hasta las guerras napoleónicas, en el periodo previo a la insurgencia (1810), es notable. De igual manera destaca el análisis pormenorizado de los distintos actores que participaron en la concesión de los diversos donativos y préstamos. Al respecto, véanse Landavazo (1999); Marichal (1989a, 1989b, 1990, 1992, 1999, 2007); Valle (1995, 1997, 2012). Asimismo, en esta historiografía resalta la atención prestada a la consolidación de vales reales como resultado de los impactos económicos y políticos que generó en Nueva España (Flores, 1969a; Hamnett, 1969; Lavrin, 1973; Marichal, 1995; Sugawara, 1967, 1976; Valle, 2012; Wobeser, 2002, 2003, 2006). 
la deuda pública, como contraparte financiera de la guerra civil novohispana, fue un espacio de contacto y tensión constante entre las entidades exactoras y los causantes fiscales del virreinato que pesó en los comportamientos y la toma de decisiones de los diversos agentes económicos.

\section{¿QUÉ DEUDA?}

Como punto previo es necesario determinar qué se consideraba en la época como una deuda del erario novohispano. Una primera acepción era la que se refería a los adeudos que se originaban por cuenta corriente como resultado de impagos, en especial a militares y empleados de la corona. Aunque hubo ejemplos de este tipo de compromisos en el reino de Nueva España y en las posesiones de la corona en el Gran Caribe y Filipinas, nunca se prolongaron de forma ostensible. Una situación que contrasta, por ejemplo, con los abultados adeudos que se crearon por cuenta corriente en el erario regio español durante el reinado de Felipe V y que se prolongaron hasta el reinado de Carlos III (Torres, 2013, pp. 293-305). En Nueva España este tipo de deudas sólo empezó a ser relevante a partir de la primera década del siglo XIX, especialmente en el rubro de los situados al Gran Caribe (Sánchez, 2015). Una segunda acepción se refería a las transferencias que ciertos ramos excedentarios del erario realizaban a otros que eran deficitarios. En este caso, adquirían la condición de suplementos "a título de reintegro". Cabe señalar que la Real Hacienda no se estructuraba como un conjunto de ramos fiscales destinados a conformar un fondo común que atendiese a la totalidad de egresos. Lejos de esta realidad, el diseño fiscal implicaba una segmentación por ramos en la que los déficits en uno de ellos eran cubiertos con los excedentes que se generaban en otros. Finalmente, se hallaba la petición de fondos ajenos o externos al real erario, los cuales representaban una carga adicional para el fisco novohispano en el momento en que se procedía al pago de intereses o a su amortización. Se trataba, como señalaron los oficiales del Tribunal de Cuentas de México en 1751, de "caudal ajeno recibido y devuelto por oficiales reales" que, según los casos, podía implicar el pago de intereses y solía aparecer en la documentación del real erario como préstamos o suplementos de corporaciones y particulares a la Real Hacienda o a la Hacienda pública (Sánchez, 2013a, p. 208).

Estos tres conceptos (deudas por cuenta corriente, suplementos a título de reintegro entre ramos fiscales y préstamos de corporaciones y particulares al erario novohispano) recibieron distinto tratamiento contable según fuese la oficina encargada de reportar los adeudos (fundamentalmente, nos referimos al Tribunal de Cuentas de México y a la Tesorería General de 
Ejército y Real Hacienda o Hacienda pública) y la finalidad del reporte. Sobre esta última destacaban dos propósitos, a saber: determinar y clasificar la deuda a fin de satisfacer el pago de intereses y, en su caso, amortizarla y llevar el control de los cargos y datas de los oficiales encargados del manejo de estos caudales. ${ }^{3}$

Si bien la modalidad de reportes enfocados a la mejoría del crédito de la Real Hacienda o la Hacienda pública ofrecía una visión amplia y sintética de muchos de los rubros que componían la deuda del fisco novohispano, adolecía de su carácter coyuntural, ya que nacía al abrigo de órdenes superiores que tenían objetivos precisos, por lo general ofrecer un plan de consolidación de la deuda y amortización de los capitales, aunque en ocasiones se efectuaron reportes con fines políticos y financieros mucho más concretos, por ejemplo la incautación de los bienes de los insurgentes, entre los que podían hallarse títulos de deuda pública. ${ }^{4}$ Todo ello derivó en una contabilidad ad hoc (agrupación o desagregación de rubros de adeudo, inclusión o exclusión de partidas) que dificulta la comparación, así como la visión diacrónica del fenómeno del endeudamiento del fisco novohispano.

Frente a estos problemas, contamos con otra modalidad de fuentes, los estados de débitos y créditos de la Tesorería General de Ejército y Real Hacienda de México o de la Hacienda pública (según periodos), elaborados por sus ministros. Documentos que presentan una virtud doble, por una parte, la homogeneidad en su elaboración, al menos a partir de $1799^{5}$ y, por otra, su amplia cobertura temporal (hemos localizado una muestra representativa entre 1799 y 1817).

El origen de estos documentos se halla en la reforma de la contabilidad de las cajas reales promovida por la Contaduría General de Indias en 1784, en la que se acometió, entre otros puntos, la clasificación de los diversos ramos que componían el real erario novohispano. A partir de entonces, las

\footnotetext{
${ }^{3}$ Como ejemplo del primer tipo de reportes, en el marco de la guerra de Independencia acudimos al proyecto elaborado por Ildefonso Maniau, contador del Real Tribunal y Audiencia de Cuentas de México, en febrero de 1817. Biblioteca Nacional, Madrid, sección manuscritos, 19710/23. Se trata de un reporte citado ampliamente por la historiografía (Hamnett, 1978, pp. 28-30, 110; TePaske, 1989, p. 73, y 1991, p. 134; Valle, 1996, p. 34; 1997, pp. 17-18, y 2013, p. 91). Otro ejemplo de proyecto de consolidación y amortización de la deuda del erario regio novohispano sería el elaborado por Antonio de Medina y Miranda para la Comisión de arbitrios en 1813 (Marichal, 1999, 2007; Sánchez, 2014a; Valle, 1997).

${ }^{4}$ Archivo Histórico de Hacienda, caja 426, exp. 31. Archivo General de la Nación (en adelante AGN).

${ }^{5}$ Dicha fuente no siempre fue homogénea en su estructura interna. Como indicó John J. TePaske, quien los trabajó de manera serial, los estados referidos al periodo 1791-1798 incluyeron los adeudos de ciertos ramos muy voluminosos (bulas de Santa Cruzada, novenos reales o vacantes de encomiendas), mientras que en los estados que iban de 1799 a 1817 no lo hicieron, al ser considerados a partir de 1799 como ramos que legítimamente pertenecían al monarca bajo la categoría de ramos comunes y no particulares del real erario (TePaske, 1989, pp. 72-73, 80).
} 
rentas se englobaron en tres grandes categorías (ramos comunes, particulares y ajenos) con ciertas subdivisiones (Sánchez, 2013a, pp. 14-26, 2015). Con este sistema de clasificación contable se delimitaba la titularidad y destino de los diferentes ramos que componían o eran administrados por el erario regio. Gracias a esta ordenación se pudo construir en los años posteriores estados de débitos y créditos de la caja matriz de México en los que se fijaban la titularidad y destino de los ramos fiscales, al igual que la premura y grado de obligación en el pago de intereses y la amortización de la deuda.

En aras de presentar la arquitectura de dichos documentos, así como sus alcances y límites, acudimos al Estado que manifiesta los débitos y créditos en que se quedó la Tesorería General de Ejército y Real Hacienda de esta Capital en 31 de diciembre de 1800, elaborado en enero de $1801 .^{6}$ En él se establecieron dos grandes categorías en materia de adeudos: los de los ramos particulares y los de los ramos ajenos, con sus respectivas subdivisiones. A su vez, se distinguió entre ramos particulares y ajenos acreedores, sobre los cuales tenía obligaciones el real erario, y ramos particulares y ajenos deudores, sobre los que tenía derechos. Con ellos, y tras los sucesivos cálculos y deducciones, se llegaba a obtener el "líquido débito de la Tesorería General". Todo ello queda sintetizado en el cuadro 1.

Este esquema destaca la existencia de ramos "gravosos al erario por ser reintegrables". Se trataba de ramos particulares acreedores en los que se asentaban los préstamos y suplementos aportados al erario regio por corporaciones y particulares, además de los suplementos otorgados por dependencias clave del fisco (en el caso de 1800, el estanco del tabaco y la Real Casa de Moneda). ${ }^{7}$ En aras de mantener el crédito, la Real Hacienda debía atender sin demora el pago de intereses de estos adeudos, cuando así estuviese estipulado, y la amortización de los capitales. En el resto de casos, se trataba de préstamos que no generaban una verdadera deuda para la corona, ya que su origen estaba en ramos del erario regio o se hallaba en ramos particulares y ajenos "que exigen reintegros" y no el reintegro de los fondos. Únicamente, en situaciones de necesidad (v. g., una epidemia, una hambruna, la minusvalía del acreedor o sus descendientes, como razones aducidas de manera frecuente), se veía como una obligación el retorno parcial de los caudales. Un hecho patente si observamos que en los encabezados de los estados de débitos y créditos se enunciaba que había ramos particulares y ajenos que "exigen reintegro en las ocasiones que necesitan sus fondos", lo cual ubicaba su devolución en el ámbito de la controversia en-

\footnotetext{
${ }^{6}$ Audiencia de México, leg. 2034. Archivo General de Indias (en adelante AGI).

${ }^{7}$ Más adelante veremos que el tratamiento de los suplementos de ambas oficinas de la Real Hacienda (la renta del tabaco y la Real Casa de Moneda de México) fue distinto al de los préstamos aportados por corporaciones y particulares.

${ }^{8}$ Las citas en Audiencia de México, legs. 2020 y 2034. AGI. Cursivas mías.
} 


\section{CUADRO 1. CLASIFICACIÓN DE LOS RAMOS PARTICULARES Y AJENOS ACREEDORES Y DEUDORES DE LA TESORERÍA GENERAL DE EJÉRCITO Y REAL HACIENDA, 1800}

Ramos particulares acreedores

Ramos ajenos acreedores

1a. clase. De los que son gravosos al erario por ser reintegrables

2a. clase. De los remisibles a España

2a. clase. Por ser remisibles a España

3a. clase. Ramos particulares que siempre son del erario

4a. clase. Ramos que exigen reintegros

4a. clase. Que exigen reintegros

Fuente: Audiencia de México, legs. 2020 y 2034. Archivo General de Indias, Sevilla.

tre el juicio de los oficiales reales y las peticiones que hiciesen sus titulares ante las necesidades que fuesen surgiendo.

Lo anterior permite entender por qué los oficiales reales de la Tesorería General de Ejército y Real Hacienda, los ministros del Real Tribunal y Audiencia de Cuentas de México o los diversos autores de proyectos de arreglo de la deuda pública novohispana centrasen sus propuestas en los ramos particulares acreedores que eran "gravosos al erario por ser reintegrables". En este sentido, y siguiendo con el ejemplo del estado de débitos y créditos referido a 1800, sobre un stock de deuda pública de 22586342 pesos (sin tomar en cuenta los diversos descuentos o los adeudos a favor del erario), constituía un adeudo "gravoso" de el 75\% de dicho monto, es decir, 17043912 pesos aportados mediante préstamos comunes o la imposición de capitales. ${ }^{9}$

Estas consideraciones generales son las que nos llevan a proponer la reconstrucción de la evolución de la deuda que fue acumulando la Tesorería General del fisco novohispano entre 1799 y 1820 a partir del rubro adeudos "gravosos al erario por ser reintegrables". Una cronología que hay que segmentar, por una parte, entre 1799 y 1809 como muestra del estado de la deuda del fisco novohispano antes de la insurgencia y, por la otra, 1810-1820 como exponente de lo acaecido con motivo de la contienda civil. Si no prolongamos el análisis hasta 1821, se debe al hecho de que no hemos podido establecer los montos para dicho año.

Dos anotaciones adicionales: fuentes y metodología. En los casos en los que no hemos localizado los estados de débitos y créditos pero contamos

\footnotetext{
${ }^{9}$ Las citas en Audiencia de México, legs. 2020 y 2034. AGI.
} 
con los libros comunes de cargo y/o de data o los estados de valores y existencias de caudales de la Tesorería General de Ejército y Real Hacienda (como sucede con los años 1805, 1811, 1818, 1819) o de la Tesorería General de Ejército y Hacienda pública $(1813,1820,1821)$ hemos procedido a reconstruirlos siguiendo la práctica de los ministros de la Caja Matriz. Al respecto es necesaria una acotación metodológica. Los contadores de la Tesorería General asentaban en los estados de débitos y créditos las existencias, es decir, la diferencia entre los cargos y las datas de cada uno de los ramos fiscales deudores y acreedores. Si bien, como hemos afirmado en otro trabajo (Sánchez, 2013a, pp. 14-26), los cargos y las datas no constituyen necesariamente los ingresos y los egresos de los ramos fiscales de la Real Hacienda, estos se vuelven una herramienta útil para observar la acumulación de tres tipos de adeudos: los que no habían sido amortizados, los intereses vencidos, que lógicamente engrosaban los débitos, y la obtención de nuevos préstamos y suplementos. Todos estos conceptos constituían "cargos", es decir, fondos sobre los cuales tenían responsabilidad los oficiales de las tesorerías del erario hasta que fuesen devueltos, total o parcialmente, o hasta que fuese transferida su responsabilidad a otros agentes del fisco, todo lo cual se consignaba en los registros de data. En el caso de que hubiese acabado el año y no se hubiese producido una de estas dos situaciones (pago o transferencia), se databan los adeudos acumulados heredados de ejercicios anteriores y los creados en el año en el ramo denominado Real Hacienda en Común para dejar la cuenta equilibrada entre cargos y datas y obtener así las existencias en cada uno de los ramos que, recordamos, eran la diferencia entre ambos conceptos. ${ }^{10}$ Dichas cantidades eran las primeras cifras que se asentaban en los ramos que tenían adeudos y gracias a ellas hemos podido reconstruir las existencias de los adeudos en los años en los que no hemos localizado los estados de débitos y créditos. ${ }^{11}$

\section{LOS PRÉSTAMOS Y SUPLEMENTOS DE CORPORACIONES Y PARTICULARES a la Tesorería General de Ejército y Real Hacienda O HACIENDA PÚBLICA (1799-1820): DEFINICIONES, MONTOS, COMPOSICIÓN Y EVOLUCIÓN}

Los adeudos gravosos para el erario novohispano en el periodo 1799-1820 se conformaron como una categoría dinámica que evolucionó a medida que las necesidades financieras de la corona no se pudieron cubrir con las rentas del fisco (impuestos, monopolios, derechos y multas) debido a las

\footnotetext{
${ }^{10}$ Un ejemplo de este ejercicio en Caja Matriz, vol. 453. AGN.

${ }^{11}$ Como muestra, véase Caja Matriz, vol. 1. AGN.
} 
sucesivas guerras y acuerdos políticos que enfrentó la monarquía española (Archer, 1981; Marichal, 1990, 2007; Ortiz, 1997; Valle, 1997, 2013).

Para comprender la evolución de los adeudos "gravosos al erario por ser reintegrables" de la Tesorería General es preciso definir sus componentes y temporalidad; para ello proponemos tres etapas, a saber: 1799-1804, $1805-1808$ y $1809-1821^{12}$

Entre 1799 y 1804, la categoría "adeudos gravosos" estuvo compuesta por tres rubros: imposición de capitales, préstamos comunes y préstamo patriótico de $1798 .^{13}$ Por imposición de capitales se entendía aquellos préstamos cuyos intereses y amortización del capital corrían por cuenta de la Real Hacienda de Nueva España; concretamente eran tres: los juros "al quitar", originados en el siglo XVII y gran parte de la primera mitad del siglo XVIII (Sánchez, 2013a); los capitales tomados del ramo de Temporalidades (fundamentalmente, de las misiones jesuíticas de Baja California y Filipinas), y el préstamo solicitado por la corona por valor de 15000000 de pesos en diciembre de 1794, con garantía del estanco del tabaco. Si bien los dos primeros eran fondos fijos para finales del siglo XVIII, sobre los que había que pagar intereses, el tercero captó capitales hasta 1803, a pesar de no haberse alcanzado la cantidad prevista inicialmente (Marichal, 1997; Valle, 2013).

Los préstamos comunes estaban conformados por una mayor variedad de componentes aunque con un ámbito común: o no exigían el pago de intereses o, si lo hacían, recaían sobre ramos fiscales otorgados por la corona al Tribunal del Consulado de Mercaderes de México y al Real Tribunal de Minería y no sobre el erario regio; corporaciones que fungieron en diversos momentos como intermediarios financieros del fisco novohispano. ${ }^{14}$ Como ejemplo de su composición tomemos el desglose que realiza el libro común de la Real Caja de México de 1810 (véase cuadro 2).

Destacan, por su relevancia, los préstamos comunes reconocidos al Tribunal del Consulado (2 400000 pesos de principales, resto de los 3000000 de pesos obtenidos por la corporación en los préstamos de 1782, 1793 y 1794) y al Real Tribunal de Minería (1 115000 pesos de los 3000000 recaudados en los mismos años) (Marichal, 1999; Valle, 1997,

${ }^{12}$ Aunque los datos que hemos podido recabar sobre los adeudos gravosos para la Tesorería General de Ejército y Real Hacienda llegan hasta 1820, en términos de lógica histórica el fenómeno llega hasta su desaparición en 1821.

${ }_{13}$ Audiencia de México, leg. 2020. AGI.

${ }^{14}$ Aparte del fondo dotal (seis al millar sobre el valor de las importaciones realizadas por Veracruz, Acapulco y San Blas), el consulado obtuvo entre 1782 y 1794 un catorce al millar adicional (Valle, 1997). En el caso del Tribunal de Minería, los mineros tuvieron que pagar granos de plata adicionales (la cantidad osciló entre uno y cuatro granos en el periodo de 1782 a 1808) por cada marco de plata que introducían en la Casa de Moneda, aparte de los ocho granos por marco que debían pagar para el fondo dotal del Tribunal (Méndez, 2012). 


\section{CUADRO 2. CARGO DE LOS PRÉSTAMOS COMUNES QUE RECONOCE LA TESORERÍA GENERAL DE EJÉRCITO Y REAL HACIENDA, 1810}

Interesados en estos préstamos

Tribunal del Consulado de México

Tribunal de Minería de México

Astillero de Coatzacoalcos

Cabildo eclesiástico de Guadalajara

Juzgado de intestados [de México]

Bienes de comunidad de Valladolid

Bienes de comunidad de Oaxaca

Expolios del señor Haro [arzobispo de México]

Bienes de comunidad de México

Premios caducos de lotería

Cabildo eclesiástico de Valladolid

Depósitos de la Real Audiencia de Guadalajara

Depósitos de la Real Audiencia de México

Juzgado de intestados de Guadalajara

Cabildo eclesiástico del Nuevo Reino de León

Capellanías de Valladolid

Obra pía de La Quemada

Tesorería de Valladolid

Temporalidades

Renta del tabaco

Total
Cargo (pesos)

2400000

1115000

640831.6

450000

257947.1

176214

150000

100000

93337.3

77000

63160.1

47422.6

40000

34575.2

30000

20000

12000

1964.5

1463

2988284.5

8699200.1

Fuente: Caja Matriz, vol. 663, f. 379. Archivo General de la Nación, México.

2013). Tras ellos aparecen diversas corporaciones novohispanas (cabildos eclesiásticos, repúblicas de indios y tribunales, caso de las reales audiencias, juzgados de intestados y de capellanías) que habían otorgado préstamos a la corona con calidad de reintegro. Había también fondos que estaban en las arcas del erario regio a título de depósito (los premios caducos -no repartidos- de la renta de lotería, los expolios del difunto arzobispo de México, Alonso Núñez de Haro, los de la obra pía de la hacienda de La Quemada o los fondos remanentes del proyecto de construcción de un astillero en Coatzacoalcos, nunca llevado a término). Finalmente, estaban los fondos del estanco del tabaco, un ramo particular remisible creado en 1764 para mandar sus ingresos netos a España. Aunque en los primeros 
estados de débitos y créditos elaborados entre 1799 y 1801 dicho rubro apareció ubicado entre los ramos particulares ajenos de "cuarta clase" (véase cuadro 1), es decir, ramos que exigían reintegros, a partir de 1802 quedó incorporado en el de préstamos comunes. Su distinta naturaleza frente a los anteriores motivó que los ministros de la Tesorería General añadiesen reiteradamente una nota al final de los estados donde señalaban que se trataba de préstamos que "pueden considerarse sin obligación de reintegro", ya que su origen estaba en un monopolio real creado para nutrir las arcas metropolitanas que, sin embargo, tuvo que realizar periódicamente "suplementos" para satisfacer los gastos en las Indias. ${ }^{15}$ Bajo esta misma consideración quedaron los fondos del astillero de Coatzacoalcos: tuvo un tratamiento de préstamo-donativo a la corona para un fin que no llegó a materializarse y que no "ameritaba" su devolución al haberse empleado el capital en otras necesidades del erario regio.

En relación con el último componente, el préstamo patriótico de 1798, se originó en el contexto de la primera guerra naval contra Gran Bretaña (1796-1802) y fue concebido como un fondo sin intereses con calidad de reintegro, en un plazo no mayor a diez años, pasados dos años de la publicación de la paz, y por el que se llegaron a colectar 836159 pesos (Marichal, 1997, pp. 133-139).

La segunda etapa de los adeudos "gravosos al erario por ser reintegrables" de la Tesorería General abarca desde 1805 hasta $1809,{ }^{16}$ y estuvo marcada por la incorporación de un nuevo adeudo, las imposiciones realizadas en la Real Caja de consolidación de vales reales, destinadas, en principio, a cubrir libranzas expedidas por la Tesorería General de la Real Hacienda metropolitana contra el fisco novohispano en el contexto de la segunda guerra naval contra Gran Bretaña (1804-1808) y los acuerdos de la corona con el gobierno napoleónico (Wobeser, 2003, p. 226). La cantidad recaudada por la desamortización de bienes raíces y la imposición de capitales de obras pías, capellanías, cofradías, catedrales, parroquias, órdenes religiosas, hospitales, casas de enseñanza y repúblicas de indios ascendió a 10509537 pesos, colectados entre 1805 y 1808, periodo en el que estuvo plenamente vigente el real decreto en Nueva España, aunque los últimos enteros en las cajas reales se realizaron hasta julio de $1811 .^{17}$

\footnotetext{
${ }^{15}$ Audiencia de México, leg. 2020. AGI.

${ }^{16}$ Aunque el real decreto de consolidación y su instrucción fueron de noviembre y diciembre de 1804, la comunicación oficial al virrey y las autoridades eclesiásticas de Nueva España se demoró hasta abril de 1805 (Wobeser, 2003, p. 51)

${ }^{17}$ Existen leves variaciones sobre el monto total colectado, véanse Marichal (1999, p. 327), Wobeser (2003, p. 79); Valle (2012, p. 112). Audiencia de México, leg. 1636. AGI. La Tesorería General llegó a computar 10511704 pesos en 1810. Audiencia de México, leg. 1145. AGI.
} 
Si bien la Tesorería General, en tanto Caja Matriz del virreinato, reconocía de manera global el adeudo por consolidación de vales reales, el pago de intereses de dicha oficina (5\% sobre los capitales impuestos) se limitaba a 5078829.3 pesos, que fueron los colectados en la diócesis de México, mientras que los intereses del resto fueron obligación de otras cajas reales del erario (Guadalajara, Puebla, Mérida, Oaxaca, etcétera). ${ }^{18}$

La tercera y última etapa de la categoría referida a "adeudos gravosos al erario por ser reintegrables" abarca de 1809 a 1821. Sin solución de continuidad, durante estos años la Caja Matriz novohispana presenció la rápida sucesión acumulativa de préstamos voluntarios y forzosos, con y sin intereses, para responder a las demandas de apoyos solicitadas tanto por las autoridades metropolitanas surgidas tras la crisis de 1808 (Marichal, 1999, 2007), en el contexto de las abdicaciones de Bayona y la invasión napoleónica, como por el esfuerzo bélico contrainsurgente (Ortiz, 1997).

La secuencia tuvo el siguiente derrotero. En 1809 se incorporaron tres nuevos adeudos "gravosos al erario por ser reintegrables": los suplementos primero y segundo y el préstamo patriótico segundo. En los dos primeros casos, se trató de suplementos a muy corto plazo (dos o tres meses) ${ }^{19}$ para cubrir el faltante de las cajas reales en su apoyo de fondos para la Junta Central y para habilitar navíos apostados en Veracruz encargados de transportar a Europa fondos del erario (Marichal, 1999, pp. 257-277; Valle, 1997, pp. 389-400). Por el suplemento primero se colectaron 3134936 pesos, ${ }^{20}$ destinándose 3000000 al pago de los apoyos que había otorgado Gran Bretaña a la nación española en su lucha contra Napoleón, los cuales fueron entregados al comisionado de S. M. británica, Andrés Cochrane Johnstone. El suplemento segundo colectó 1564435 pesos entre noviembre de 1809 y enero de 1810, ${ }^{21}$ y su propósito fue "socorrer las urgentísimas necesidades de la península". Unos fondos que fueron transportados a Cádiz en el navío Asia. ${ }^{22}$

El préstamo patriótico segundo (denominado así para distinguirlo del préstamo patriótico de 1798, que pasó a llamarse "primero" o "antiguo") fue levantado a partir de agosto de 1809. El erario ofreció por término de cinco años un interés de $6 \%$, lo cual constituyó "un premio sin ejemplar" (Jáuregui, 1999, pp. 236-242; Valle, 1997, pp. 393-395). El monto obteni-

${ }^{18}$ Audiencia de México, leg. 1145, f. 636. AGI.

${ }^{19}$ Caja Matriz, vol. 17, f. 235. AGN.

${ }^{20}$ Caja Matriz, vol. 17, ff. 235-236v. AGN. Esta cifra la eleva Guillermina del Valle a 3193436 pesos a partir de fuentes consulares (Valle, 2013, p. 80).

${ }^{21}$ Caja Matriz, vol. 17, ff. 237-239v y vol. 716, f. 209. AGN.

${ }^{22}$ Gazeta del Gobierno de México, sábado 2 de diciembre de 1809, t. XVI, núm. 144, p. 1088. Audiencia de México, leg. 1475. AGI. 
do no cubrió las expectativas de las autoridades ya que apenas se recaudó entre agosto de 1809 y diciembre de 1810 la cantidad de 380402.6 pesos. $^{23}$

En 1810 se añadieron tres nuevos adeudos: los suplementos tercero y cuarto y el préstamo patriótico de 20000000 de pesos. Por lo que respecta a los suplementos estamos, una vez más, ante adeudos a corto plazo como los levantados en 1809. En el caso del suplemento tercero se recaudaron 596210 pesos entre julio y agosto de $1810,{ }^{24}$ destinándose los fondos a habilitar el navío Baluarte, mientras que por el suplemento cuarto se obtuvieron 1170476 pesos, entre noviembre de 1810 y marzo de 1811, con los que se habilitó el navío Miño. ${ }^{25}$

De una naturaleza muy distinta fue el préstamo patriótico de 20000000 de pesos para socorro de la península, no sólo por el monto solicitado, el más alto en la historia de la Real Hacienda de Nueva España, sino también por todo el acompañamiento institucional que generó (manifiesto, reglamento, creación ex profeso de una junta del préstamo con la presencia de ministros de la Real Hacienda y de representantes de los tres consulados de comercio de Nueva España, aprobación de una fiscalidad extraordinaria para el pago de intereses y la amortización de capitales, etc.) (Anna, 1981, pp. 172-173; Jáuregui, 1999, pp. 242-248; Marichal, 1999, pp. 264266; Valle, 1997, pp. 400-409).

El estallido de la insurgencia en septiembre de 1810 impidió obtener las cantidades esperadas y que los fondos se empleasen en lo previsto originalmente. La recolección del préstamo se inició en septiembre de 1810 y se prolongó hasta mayo de 1811, cuando se canceló como resultado de la guerra civil (Valle, 1997, p. 408). ${ }^{26}$ Según un reporte de 1813, hasta el

${ }^{23}$ Caja Matriz, vol. 17, ff. 240-241v y vol. 716, ff. 257-258v. AGN.

${ }^{24}$ Caja Matriz, vol. 716, ff. 210-211. AGN. Gazeta del Gobierno de México, martes 31 de julio de 1810, t. I, núm. 83, pp. p. 623-624. Audiencia de México, leg. 1475. AGI.

${ }^{25}$ Caja Matriz, vol. 716, ff. 252-254 y Caja Matriz, vol. 306, f. 184. AGN. Consideramos que los suplementos para habilitar navíos se obtuvieron rápidamente no sólo porque eran préstamos a muy corto plazo, sino también por el hecho de que las naves abrieron registros para particulares, lo cual debió facilitar los negocios de los mercaderes, quienes aportaron la mayoría de estos suplementos (Valle, 1997, 2013). A la fidelidad a la corona, se añadió el interés personal. Por ejemplo, en 1810, el navío Baluarte abrió el registro para particulares por valor de 2500000 pesos. Gazeta del Gobierno de México, viernes 10 de agosto de 1810, t. I, núm. 86, pp. 647-648.

${ }^{26}$ En noviembre de 1810 se ordenó levantar otro préstamo, por un valor de 2000000 de pesos "con destino al urgente socorro de la península" (Anna, 1981, pp. 172-173; Valle, 1997, pp. 411-413), iniciándose la recolección en la ciudad de México en diciembre de 1810. Sin embargo, este adeudo no aparece en la contabilidad de la Tesorería General de Ejército y Real Hacienda. Consideramos que la razón se halla en que se trataba de un préstamo en el que "los individuos de esta vecindad y comercio [de México]" habían "facilitado caudales en la plaza de Veracruz para el propio despacho del navío inglés el Implacable, que conduce el urgente socorro a la Península". Suplemento a la Gazeta del Gobierno de México, viernes 7 de diciembre de 1810, t. I, núm. 147, p. 1021. $\mathrm{Al}$ respecto véase Valle (1997, p. 414). Para los préstamos y suplementos colectados en la caja de Veracruz en 1810, véase Caja Matriz, vol. 749. AGN. 
31 de diciembre de 1812 habían ingresado en las cajas de los consulados de México, Veracruz y Guadalajara (corporaciones encargadas de colectar el préstamo) un total de 2019305.6 pesos, de los cuales 449044.1 pesos correspondieron a los sobrantes de los impuestos creados para financiar el empréstito, de manera tal que el capital aportado por corporaciones y particulares ascendió a 1570261.5 pesos. $^{27}$

En 1811 apareció el último rubro en la categoría de adeudos "gravosos al erario por ser reintegrables": el suplemento quinto. Un epígrafe que acabó teniendo una composición extremadamente compleja puesto que tuvo que responder a las exigencias de apoyos financieros por parte de la Regencia y a los planteados por los costos militares emanados de la guerra civil.

En un primer momento, el virrey Francisco Xavier Venegas (18101813) ordenó levantar un suplemento adicional destinado al "despacho de los navíos de guerra" que estaban apostados en Veracruz con destino a Cádiz. Un suplemento a corto plazo, por lo general de tres meses, que inició su colecta en marzo de $1811 .^{28}$ Por este concepto, diversos mercaderes consulares y particulares aportaron 742250 pesos (Valle, 1997, pp. 417, 444-445). ${ }^{29}$ Sin embargo, el bloqueo de los caminos y la marcha de guerra contra los insurgentes motivaron que se incorporasen nuevos recursos al suplemento quinto que, por orden de importancia, fueron los suplementos de la Real Casa de Moneda a la Tesorería General de Ejército y Real Hacienda "con calidad de reintegro" del valor de las platas que la tesorería remitiese a la ceca en un futuro para su amonedación, los de la tesorería del Tribunal del Consulado de México "por cuenta de los productos o fondos del préstamo patriótico de 20 millones con calidad de reintegro por la Real Hacienda y para sus urgentes atenciones", los del Cabildo catedral metropolitano para los mismos fines y, finalmente, diversos fondos de los bienes de comunidad, en este caso de la intendencia de Oaxaca ${ }^{30} \mathrm{El}$ valor de los distintos componentes del suplemento quinto fue como se muestra en el cuadro 3.

Podemos apreciar que la Real Casa de Moneda se transformó en un proveedor fundamental de recursos $(46 \%)$ que se emplearon para atender las necesidades de una Tesorería General que veía cómo las fuentes tradicionales de ingresos decaían rápidamente, mientras que los gastos bélicos se elevaban. A continuación, encontramos al Tribunal del Consulado de México (30\% del suplemento quinto), quien aportó fondos de los ramos fiscales que gestionaba desde septiembre de 1810 con motivo del préstamo

${ }^{27}$ Estos datos reflejaban los enteros realizados en plata acuñada y vajilla en las cajas de los consulados de México, Veracruz y Guadalajara. Audiencia de México, leg. 1145, f. 608. AGI.

${ }^{28}$ Caja Matriz, vol. 306, f. 175. AGN.

${ }^{29}$ Caja Matriz, vol. 306, ff. 175-177v. AGN.

${ }^{30}$ Caja Matriz, vol. 306, ff. 175-177v. AGN. 
CUADRO 3. COMPOSICIÓN DEL SUPLEMENTO QUINTO A LA TESORERÍA GENERAL DE EJÉRCITO Y REAL HACIENDA, 1811

Razón

Real Casa de Moneda

Tesorería del Consulado de México

Particulares

Cabildo catedral metropolitano

Bienes de comunidad

Total
Cuenta del cargo

(en pesos)

1602454.4

1059721.4

742250

100000

12335

3516761

Fuente: Caja Matriz, vol. 306, ff. 175-177v. Archivo General de la Nación, México.

patriótico de 20000000 (especialmente, el aumento de 2\% de alcabala, los impuestos al cacao y la cera importados y los aplicados a los bienes procedentes de Manila) (Valle, 1997, pp. 404-405); pero también del fondo extraordinario de la avería del catorce al millar (en este caso para la creación de un camino militar que abriese las rutas interceptadas por los insurgentes). En tercer lugar se ubicaron los fondos aportados por particulares, en su mayor parte, como vimos, miembros del Consulado de Mercaderes de México (21\%), seguidos a mucha distancia de otros proveedores que, en el caso de 1811, fueron el Cabildo catedral metropolitano (3\%) y las comunidades de indios de Oaxaca $(0.4 \%)$.

A partir de 1812 ya no se distinguió en la contabilidad de la Tesorería General entre los distintos suplementos recaudados desde 1809. Desde entonces, y bajo la categoría genérica de suplementos, quedaron integradas las existencias de los adeudos de los suplementos primero al quinto (1809-1811), las provisiones que realizaron anualmente la ceca capitalina y el Tribunal del Consulado de mercaderes (en este caso, reiteramos, por los ingresos fiscales del préstamo patriótico de 20000000 de pesos que gestionaba) y las nuevas aportaciones que efectuaron particulares y corporaciones con base en préstamos, mayoritariamente forzosos desde 1812, además de pequeñas partidas originadas en excedentes de ciertos ramos fiscales (por ejemplo, la renta del vino mezcal o las alcabalas de aduanas foráneas a la capital). ${ }^{31}$

${ }^{31}$ Por ejemplo, en 1818, el rubro suplementos estuvo compuesto de las siguientes partidas: sobre un cargo total de 12623409.5 pesos, $86 \%$ correspondió a las existencias heredadas de los adeudos por concepto de suplementos de años anteriores -1809-1817- (10 860143.4 pesos), 10.5\%, a aportaciones del Tribunal del Consulado por los impuestos del préstamo de 20000000 (1 330174.7 pesos), 1.6\% a suplementos de la Real Casa de Moneda (204 382.6 pesos), 1.2\% por 
Con estas definiciones básicas de los componentes de los adeudos "gravosos al erario por ser reintegrables" podemos establecer el stock de deuda y su composición entre 1799 y 1820 (véase gráfica 1).

La evolución de los débitos gravosos evidencia que la Tesorería General del erario novohispano experimentó un endeudamiento creciente entre 1799 y 1820 al pasar, respectivamente, de un monto total de 18532400 pesos a 41788770 pesos, lo que implicó una tasa de crecimiento anual de $3.8 \%$. Un incremento que, sin embargo, tuvo dos etapas muy marcadas: por una parte, la que va de 1799 a 1809 , ubicada entre los impactos financieros de la primera guerra naval (1796-1802) y los apoyos otorgados a la Junta Central en su lucha contra el ejército napoleónico (1808-1809); en este periodo hubo un endeudamiento mucho más acelerado, con una tasa de crecimiento anual de $4.5 \%$, frente a $3.4 \%$ vivido entre 1810 y 1820 , en el contexto de la guerra civil novohispana. ${ }^{32}$ La lógica de ambas dinámicas no se ubica, claro está, en la importancia de las necesidades bélicas, sino en el estado del fisco novohispano y de la propia economía virreinal. Mientras que en el primer periodo nos hallamos ante un erario que logró su cúspide recaudatoria (con un ingreso promedio anual un poco superior a los 20000000 de pesos en el quinquenio 1795-1799) al abrigo de una economía en expansión (Jáuregui, 1999; Marichal, 1999), en la década de 1810 se evidenciaron los estragos económicos y fiscales de la guerra civil (Jáuregui, 1999; Sánchez, 2014a, 2014b; TePaske, 1989, 1991; Valle, 1997, 2013).

Por otra parte, se constata que la evolución de los distintos rubros que componían los débitos "gravosos al erario por ser reintegrables" fue también dispareja. Siguiendo su temporalidad, vemos que la imposición de capitales representó un débito promedio anual de 8199157 pesos entre 1799 y 1820 , con un coeficiente de variación muy bajo, del orden de 7\%, lo que lo convierte en el rubro más estable de los adeudos gravosos al erario regio. La razón se halla, como vimos, en que estaba conformado por dos partidas cerradas a la contratación de nuevos adeudos durante nuestro periodo de estudio (juros y temporalidades), mientras que la tercera (el préstamo de

fondos enterados por las aduanas foráneas a partir de los impuestos del préstamo de 20000000 (155 840.5 pesos), $0.5 \%$ a partir de los impuestos del mismo préstamo colectados por el Consulado de Veracruz (67 824.6 pesos), siendo el resto partidas muy menores (5 000 pesos de un suplemento del Tribunal de Minería, 42.3 pesos por bienes de comunidad y 1.4 pesos de la renta del mezcal) que en total no sumaron ni $0.04 \%$ del cargo total. Caja Matriz, vol. 453, ff. 447-457v. AGN.

${ }^{32}$ Este desigual comportamiento, antes y después de 1810, ya fue consignado por John J. TePaske, el matiz está en la proporción que alcanzó el fenómeno, ya que nuestros datos no coinciden plenamente con los apuntados por dicho autor. No hemos podido contrastarlos al no ser explícitos los criterios con los cuales construyó su serie de adeudos de la Tesorería de México entre 1791 y 1817 (TePaske, 1989, p. 80, 1991, p. 106). 


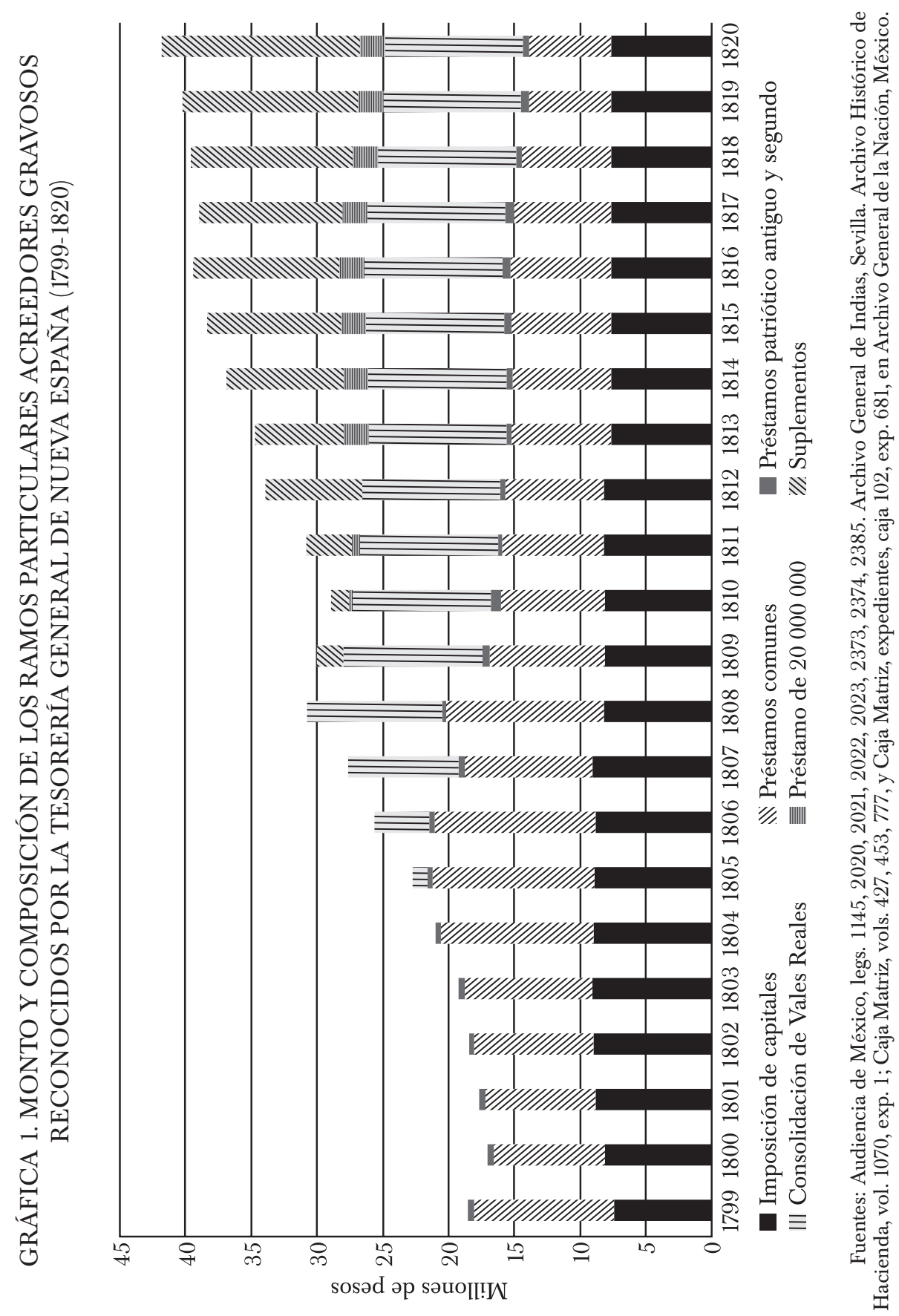


15000000 de pesos de 1794) sólo estuvo activo, y por tanto generando adeudos crecientes hasta 1803. A partir de entonces, los montos reconocidos por la imposición de capitales fueron a la baja muy lentamente, al pasar de 9038895 pesos en 1803 a 7649010 pesos en 1820, como resultado de la amortización de principales del préstamo de 15000000 de pesos.

A continuación hallamos tres rubros con una variabilidad media, los préstamos comunes (coeficiente de variación de 22\%), el préstamo patriótico antiguo y segundo (de 22\%) y la consolidación de vales reales (de 29\%). En el caso de los préstamos comunes, con un adeudo promedio de 8768579 pesos entre 1799 y 1820 , tuvo un movimiento ascendente entre el bienio 17991800 (con un adeudo promedio aproximado de 9500 000) y el bienio 1805-1806 (con 12200000 pesos de promedio), para ir paulatinamente cayendo hasta el bienio 1819-1820 (6 200000 pesos de promedio). Tres fueron las razones de esta evolución. En primer lugar, las participaciones que realizó el estanco del tabaco a la Tesorería General. Mientras que durante el periodo previo a la guerra civil su participación fue elevada y creciente (en 1800 sus existencias en los préstamos comunes sumaron 1070001 pesos para alcanzar los 5988284 pesos en 1805), a partir de 1809 decayó aportando un promedio de 2900000 pesos durante el bienio 1815-1816. En segundo lugar, el reconocimiento del préstamo-donativo para el astillero de Coatzacoalcos, el cual redujo su participación entre 1800 y 1804, al pasar respectivamente de un adeudo de 1198880 pesos a 640831 pesos. $^{33}$ Sin embargo, cabe recordar que los ministros de la Tesorería General no consideraban estas partidas como verdaderos adeudos gravosos para el real erario al no ser reintegrables, a diferencia del resto de los componentes del rubro préstamos comunes (véase cuadro 2). En ellos también se produjo una reducción de los adeudos gravosos durante la década de 1810. Mientras que el Tribunal del Consulado mantuvo su posición acreedora por un valor de 2400000 pesos, resto de los 3000000 de pesos facilitados en los préstamos de 1782, 1793 y 1794 (Marichal, 1999; Valle, 1997), el Tribunal de Minería, que había aportado el mismo monto, fue recuperando el capital prestado, bien directamente o como intermediario. En 1810 la Tesorería General le adeudaba 1115000 pesos, mientras que en 1816 la cifra se había reducido a 618678 pesos..$^{34}$ Un logro que fue el resultado de la capacidad de negociación que ejerció el Tribunal de Minería y por la cual obtuvo, en 1799, que la Caja Matriz le abonase mensualmente 10000

${ }^{33}$ Audiencia de México, legs. 1145, 2020, 2023, 2034, 2374, 2385. AGI, Sevilla; Archivo Histórico de Hacienda, vol. 1070, exp. 1e. AGN.

${ }^{34}$ Otras reducciones, si bien muy menores, en los adeudos, ocurrieron en los bienes de comunidad (una reducción de 3916 pesos entre 1810 y 1816) y en los de los juzgados de intestados (que disminuyó en 57926 pesos en los mismos años). Caja Matriz, vol. 663, fj. 379. AGN, México; Biblioteca Nacional, Madrid, sección manuscritos 19710/23, f. 2. 
pesos hasta la cancelación del adeudo (Méndez, 2012, p. 42). Pagos que no fueron interrumpidos ni siquiera en los peores años de la guerra civil (bienio 1812-1813), aunque el monto aportado por la Tesorería General fue variable. ${ }^{35}$ Consideramos que este trato favorable se logró por la política que tenían las autoridades y los actores económicos de la época sobre un sector que era percibido como el motor de la economía mercantil del virreinato, al que se debía proteger.

Los préstamos patrióticos antiguo (1798) y segundo (1809), que hemos agrupado tal y como lo realizaron los propios actores de la época, dada su condición de préstamos a mediano y largo plazos, ${ }^{36}$ aportaron escasos recursos por comparación con otros préstamos (836 159 pesos en el caso del antiguo y 380402 pesos en el segundo). El adeudo reconocido por la Tesorería General progresivamente se redujo, de manera que en 1816 ya sólo sumaba la cantidad de 395663 pesos (35\% del capital inicial). ${ }^{37} \mathrm{Si}$ la deuda consignada ese mismo año en el estado de valores y débitos de la Tesorería General sumó 616985 pesos se debe a la incorporación de réditos caídos y a la inclusión de partidas "virtuales" para ajuste contable procedentes de otras cajas reales y oficinas, como la aduana de Puebla o la de Mérida, a partir de ramos como "suplementos" u "otras tesorerías" ${ }^{38}$

El último componente con variabilidad media, la consolidación de vales reales, tuvo una progresión ascendente entre 1805 , cuando se inició su colecta y se obtuvieron 1093998 pesos (Lavrin, 1973), hasta 1809, cuando el débito registrado alcanzó la cantidad de 10511704 pesos. A partir del año siguiente, el monto descendió levemente a 10496397 pesos, cantidad que la Tesorería General reconocía todavía a finales de 1817. Por tanto, fue un adeudo que no experimentó amortizaciones notables durante la década de $1810 .^{39}$

Finalmente, están dos rubros con una elevada variabilidad, el préstamo de 20000000 de pesos (coeficiente de variación de 40\%) y los denominados genéricamente en la contabilidad como suplementos a partir de 1812 (coeficiente de variación de 52\%). Por lo que respecta al primero, con un adeudo promedio de 1592187 pesos entre 1810 y 1820, mostró una evolución creciente entre 1810, con un débito reconocido por la Tesorería General de 205887 pesos, hasta 1813, cuando la cifra sumaba ya 1887550 pesos. Este monto se mantuvo hasta 1820 sin amortizarse capitales. ${ }^{40}$ Por lo que atañe

${ }^{35}$ Caja Matriz, vol. 392, fj. 465-466 y Caja Matriz, vol. 365, fj. 995-999v. AGN.

${ }^{36}$ Como ejemplo, ver el tratamiento conjunto que da Ildefonso Maniau a su informe de 1817. Biblioteca Nacional, Madrid, sección manuscritos 19710/23, f. 2.

${ }^{37}$ Biblioteca Nacional, Madrid, sección manuscritos 19710/23, f. 2.

${ }^{38}$ Ejemplos de esta situación en Caja Matriz (vol. 479, f. 326). AGN.

${ }^{39}$ Audiencia de México, leg. 1145 y Audiencia de México, leg. 2385. AGI.

${ }^{40}$ Audiencia de México, leg. 1145 y Audiencia de México, leg. 2385. AGI. 
a los suplementos, fue la partida que más incrementos tuvo en términos absolutos y relativos durante su periodo de existencia (1809-1821) frente al resto de los adeudos gravosos para la Tesorería General. Si bien contó con un débito anual promedio de 8560304 pesos, pasó de reconocer apenas 1970433 pesos en 1809, como existencias de los suplementos primero y segundo y del préstamo patriótico segundo, a enfrentar un adeudo de 15048171 pesos en 1820. En esta última cantidad se incluyeron las existencias de los suplementos a corto plazo (enumerados, como vimos, en la contabilidad del primero al quinto), los suplementos de la Real Casa de Moneda a la Tesorería General ${ }^{41}$ y del Tribunal del Consulado de México a cuenta de los impuestos que gestionaba por el préstamo patriótico de 20000000 de pesos. A ello se agregó la sucesión de préstamos forzosos y voluntarios que establecieron los virreyes Francisco Javier Venegas y Félix María Calleja entre 1812 y 1815 en su búsqueda por cubrir el déficit generado por el desbalance entre los elevados gastos bélicos y de administración del gobierno virreinal y la caída de los ingresos tributarios ${ }^{42}$ (véase cuadro 4).

De las consultas de esta información se desprenden varios aspectos. En primer lugar, la enorme suma que llegó a reconocer la Tesorería General de Ejército y Real Hacienda y de Hacienda pública por la búsqueda de fondos para apoyar a las autoridades metropolitanas (1808-1811) y para hacer frente a la insurgencia (1811-1815), que alcanzó la cifra de 14511931 pesos. En segundo lugar, la capacidad menguante de la Caja Matriz para amortizar los capitales. Mientras que los suplementos de 1809 estaban prácticamente devueltos al año siguiente, los obtenidos en 1810 presentaban adeudos considerables en 1811, a pesar de tratarse de suplementos a muy corto plazo, por lo general entre dos y tres meses. No sólo eso, el cuadro muestra la imposibilidad de la Tesorería General para amortizar cantidad alguna de los seis préstamos recaudados entre 1812 y 1815 , en el contexto de la guerra civil novohispana, al menos hasta 1817. Un incumplimiento especialmente notable a partir del bienio 1812-1813 que marcaría la evolución posterior (Anna, 1981, p. 174; Gómez, 1995, pp. 260-270; Valle, 1997, pp. 471-550, 2013, pp. 81-91).

La insolvencia llegó a tal punto que se suspendió el pago de réditos en la mayoría de los préstamos contratados por la Caja Matriz, lo que derivó en que los débitos por "réditos vencidos" creciesen notablemente. Si en 1813 su monto fue de 1291732 pesos, al llegar 1817 casi se triplicó al as-

${ }^{41}$ En marzo de 1816, la contaduría de la Real Casa de Moneda informó que, entre 1811 y marzo de 1816, había hecho suplementos por valor de 5826792 pesos a la Tesorería General. Audiencia de México, leg. 1830. AGI.

${ }^{42}$ Para el contexto y las circunstancias en los que se obtuvieron estos préstamos durante la guerra civil (Valle, 1997, pp. 471-550, 2013, pp. 81-91). 


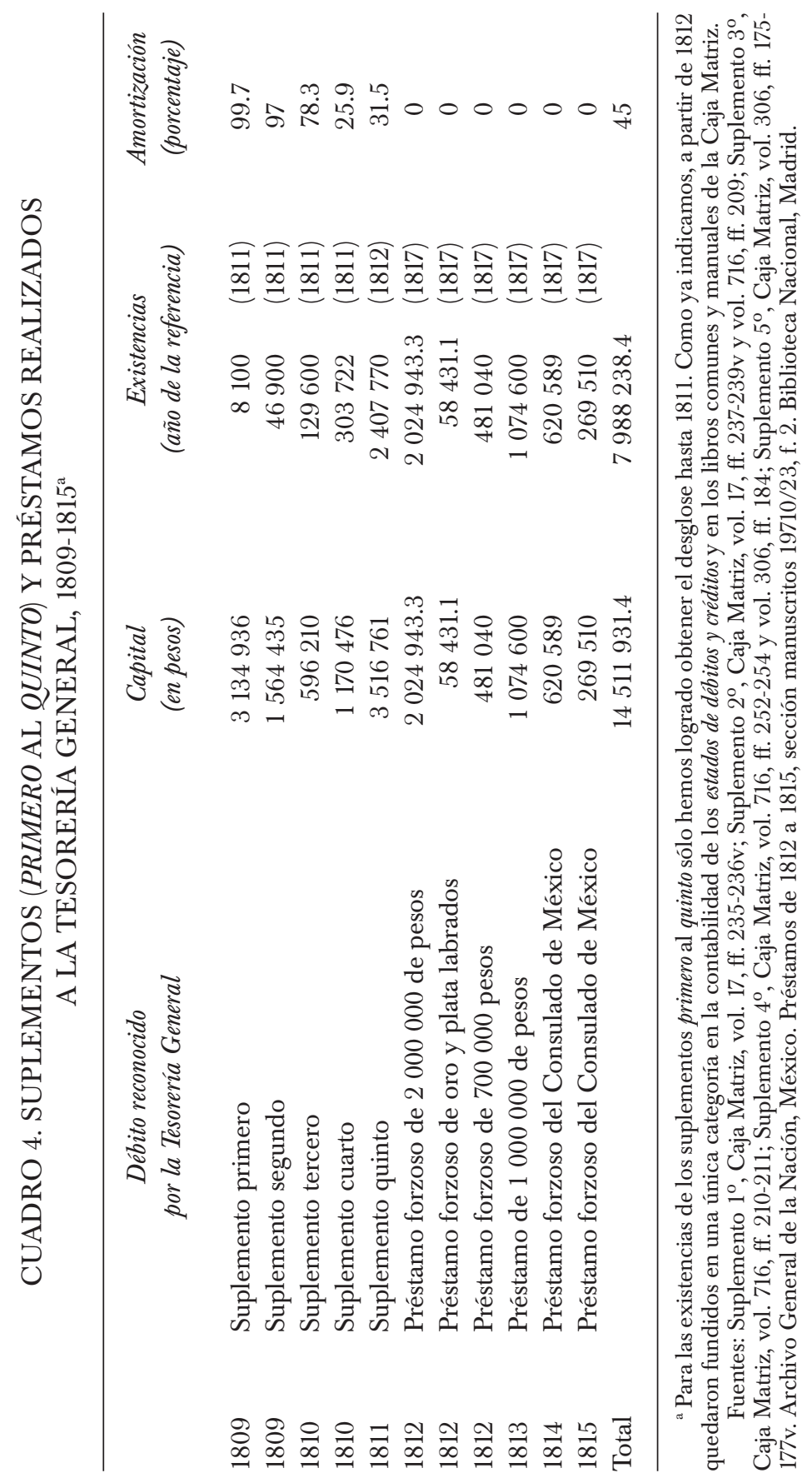


cender a 3860795 pesos. ${ }^{43} \mathrm{El}$ corolario fue la pérdida del crédito por parte de la Tesorería General, lo que era sinónimo del gobierno virreinal. A partir de 1816 ya sólo quedaron los recursos de los suplementos de las rentas de la corona para cubrir los déficits de la Tesorería General de Ejército y Real Hacienda, algo que pudo realizarse gracias a la lenta mejoría del estado de guerra y de la economía que experimentó el virreinato de Nueva España a partir del segundo lustro de la década de 1810 (Sánchez, 2014b).

Los intentos por recuperar el crédito correspondieron a una etapa posterior, durante el gobierno del virrey Apocada (1816-1821), quien llegó a vanagloriarse de no haber solicitado préstamos durante su gobierno, a diferencia de sus predecesores ${ }^{44}$ (Anna, 1981, pp. 177-178; Hamnett, 1978, pp. 111-116; TePaske, 1991, p. 134) y de poder iniciar la devolución de parte de los capitales. ${ }^{45}$ Incluso se reactivó, si bien parcialmente, el pago de los intereses de los adeudos que reconocía la Caja Matriz. Así, por ejemplo, en un informe de la Tesorería del Tribunal del Consulado de México de junio de 1823 al Ministerio de Relaciones Interiores y Exteriores, encabezado entonces por Lucas Alamán, se señaló que los intereses de los préstamos otorgados por corporaciones y particulares en 1782, 1793 y 1794 tenían cubiertos sus intereses hasta el 1 de mayo de 1821, mientras que en el caso del préstamo patriótico de 20000000 de pesos de 1810 y los prestamos forzosos de 1814 y 1815, los tenían cubiertos hasta el 31 de diciembre de 1820 . Préstamos, como vimos, en los que la corporación mercantil capitalina había desempeñado un papel clave (Valle, 1997, 2013), y cuyos titulares vieron cómo se reactivó el pago de intereses ante la mejoría de la actividad económica, lo que permitió que las rentas que estaban estipuladas para el pago de intereses por parte del Consulado de Mercaderes de México fuesen a parar a su destino original. ${ }^{46}$ Incluso, se procedió a cubrir parte de los réditos atrasados de los capitales impuestos en la consolidación de vales reales, los cuales estaban pendientes de pago en la Tesorería General desde 1813. ${ }^{47} \mathrm{Al}$ respecto es sintomático que los incumplimientos se reiniciasen a

${ }^{43}$ Audiencia de México, leg. 1145. AgI. Sección manuscritos 19710/23, f. 2. Biblioteca Nacional, Madrid.

${ }_{44}$ Audiencia de México, leg. 2385. AGI.

${ }^{45}$ En enero de 1820, se informó al público de la capital que "a propuesta del Real tribunal del Consulado [...] y de orden del Excmo. Sr. Virrey" se había amortizado, con fecha de finales de diciembre de 1819, "la cuarta parte del préstamo forzoso del año de 1814 con la cantidad de 158245 pesos cinco reales nueve granos estando corriente el pago de réditos; lo que se inserta [...] para noticia de los prestamistas y del público". Gazeta del Gobierno de México, 15 de enero de 1820, t. XI, núm. 8 , p. 58.

${ }^{46}$ Consulado, AGN, caja 269, exp. 14.

${ }^{47}$ El gobierno virreinal informó en marzo de 1820 que se habían satisfecho réditos atrasados de consolidación por valor de 58144 pesos. Incluso, se añadió, la tesorería de Real Hacienda de Zacatecas también había procedido a amortizar adeudos por valor de 92197 pesos. Gazeta del Gobierno de México, 4 de marzo de 1820, t. XI, núm. 20, pp. 224-225. 
partir de 1821. El estallido de la rebelión militar promovida por Agustín de Iturbide en febrero de dicho año volvió a someter al erario novohispano a un estado de guerra.

\section{CONCLUSIONES}

La crisis financiera del erario novohispano fue un proceso paulatino que tomó forma entre las décadas de 1780 y 1820 (Anna, 1981; Hamnett, 1978; Jáuregui, 1999; Marichal, 1992, 1999; TePaske, 1989, 1991; Valle, 1997, 2013; Vega, 1990; Wobeser, 2003). Sin embargo, consideramos que este fenómeno ha de pautarse en su temporalidad y, para ello, pensamos que un criterio adecuado radica en la determinación de la capacidad del fisco para cumplir con el pago de intereses y los plazos de amortización de los préstamos, en el entendido de que el problema no radicaba tanto en el elevado stock de deuda pública per se, sino en la solvencia del erario novohispano para atender sus obligaciones. ${ }^{48}$

$\mathrm{Si}$, como hemos mostramos en un trabajo previo (Sánchez, 2015), la Real Hacienda no sólo acumuló una deuda muy escasa entre las décadas de 1700 y 1780, sino que cumplió con sus compromisos de manera consistente, lo que le granjeó el crédito entre las corporaciones y los particulares novohispanos, queda claro que la década de 1790 marcó una ruptura en esta relación. A partir de entonces se inició el impago parcial y selectivo de los intereses de la deuda y la amortización de capitales. Por ejemplo, en algunos de los préstamos colectados entre 1793 y 1794, en los que la Real Hacienda acordó con los prestamistas que serían amortizados en un plazo no mayor a dos años, esto no había sucedido todavía, como vimos, en 1808. Un impago que se hizo especialmente gravoso en el caso de los préstamos intermediados por el Tribunal del Consulado de México, frente a los aportados por el Tribunal de Minería. Otro ejemplo se refiere a la consolidación de vales reales (1804). Según un reporte de 1809, la Tesorería General arrastraba entonces una demora en el pago de intereses del orden de 43\%. En la contraparte, se hallaba el préstamo de 15000000 de pesos con hipoteca del estanco del tabaco (1794), en el que todo parece indicar que sí se cumplió cabalmente con los acreedores (Sánchez, 2015).

La crisis imperial de 1808 y el estallido de la insurgencia en 1810 agravaron la situación. Del impago parcial y selectivo se fue caminando hacia

\footnotetext{
${ }^{48}$ En este sentido es relevante acudir al ejemplo del caso británico, en el cual se combinó la enorme deuda acumulada con motivo de las guerras contra España y Francia a lo largo del siglo XVIII y la solvencia mostrada para atender el pago de intereses y los plazos de amortización, lo que redundó en el mantenimiento del crédito entre la ciudadanía (Stasavage, 2003).
} 
el impago general de los intereses de la deuda, toda vez que la capacidad para la amortización de capitales fue marginal, con el caso del Tribunal de Minería como único ejemplo relevante. Si en un primer momento la Tesorería General pudo mantener los nuevos compromisos financieros adquiridos, como ocurrió con los suplementos primero y segundo para el pago de los apoyos de Gran Bretaña o la habilitación de navíos de guerra, en los que se iban a trasladar capitales del erario regio a las autoridades españolas ubicadas en Cádiz, el retorno de los suplementos sucesivos (del tercero al quinto) fue mucho más difícil y accidentado. El punto final se produjo en el crítico bienio de 1812-1813. El impago de intereses prácticamente se generalizó y prolongó hasta 1817. La quiebra financiera de la Tesorería General se hizo realidad. A partir de dicho bienio, el erario del gobierno virreinal quedó abocado al pago, en muchas ocasiones parcial, de la contrainsurgencia y de la administración hacendaria y de justicia (Sánchez, 2014b), posponiendo cualquier otra obligación, como en el caso del servicio de la deuda pública. El resultado fue la pérdida del crédito entre las corporaciones y los particulares novohispanos (Anna, 1981; TePaske, 1989, 1991; Valle, 1997, 2013). A partir de 1816, los déficits de la Tesorería General de Ejército y Real Hacienda se cubrieron mayoritariamente con transferencias de las propias rentas de la corona, a título de suplementos (la Real Casa de Moneda, los impuestos al comercio, interno y externo, cedidos al Tribunal del Consulado de México o el estanco del tabaco, como ramos principales). Esta realidad transmite una dualidad. Por una parte, la capacidad del erario regio para volver a enfrentar la mayor parte de sus obligaciones fiscales a partir de su propia estructura de rentas. La inoperancia creciente de la guerrilla insurgente y la consiguiente mejora de la situación económica lo permitieron. Por la otra, se trató de una práctica forzada por las circunstancias ya que la fuente del dinero, el crédito, se había cegado. De hecho, la mejoría fiscal ocurrida entre 1817 y 1820 sólo permitió una reactivación parcial del pago de los intereses de la deuda y de la amortización de capitales. Todo se pospuso a la obtención de una victoria militar absoluta que nunca se produjo.

\section{LISTA DE REFERENCIAS}

Anna, T. (1981). La caída del gobierno español en la Ciudad de México. México: Fondo de Cultura Económica.

Archer, CH. I. (1981). El ejército en el México borbónico 1760-1810. México: Fondo de Cultura Económica.

BazAnt, J. (1968). Historia de la deuda exterior de México (1823-1946). México: El Colegio de México. 
CовÁ, L. (2014). La Hacienda pública en Yucatán: las vicisitudes del erario nacional y estatal, 1810-1839 (tesis de doctorado en Historia Moderna y Contemporánea). México, Instituto de Investigaciones Dr. José María Luis Mora.

FLOREs, R. (1969a). La consolidación de vales reales en la economía, la sociedad y la política novohispanas. Historia Mexicana, 18(3), 334-378.

FLOREs, R. (1969b). La contrarrevolución en la independencia. Los españoles en la vida política, social y económica de México (1804-1838). México: El Colegio de México.

Gómez, C. (1995). Las arcas de la Iglesia al servicio de la guerra contrainsurgente: Puebla, 1810-1812 (pp. 269-272). En M. P. MARTínEz (coord.), Iglesia, Estado y economía. Siglos XVI al XIX (pp. 269-272). México: Universidad Nacional Autónoma de México/Instituto de Investigaciones Dr. José María Luis Mora.

Hamnett, B. (1969). The appropriation of Mexican Church wealth by the Spanish bourbon government: the consolidation de vales reales, 1805-1809. Journal of Latin American Studies, 1(2), 85-113.

Hamnett, B. (1978). Revolución y contrarrevolución en México y el Perú (liberalismo, realeza y separatismo, 1800-1824). México: Fondo de Cultura Económica.

JÁuregui, L. (1999). La Real Hacienda de Nueva España. Su administración en la época de los intendentes, 1786-1821. México: Universidad Nacional Autónoma de México.

Landavazo, M. A. (1999). La fidelidad al rey. Donativos y préstamos novohispanos para la guerra contra Napoleón. Historia Mexicana, 230, 493-521.

LAVRIN, A. (febrero, 1973). The execution of the law of consolidation in New Spain: Economic Aims and Results. The Hispanic American Historical Reviewe, 53(1), 27-49.

Marichal, C. (1989a). El Tratado de Subsidios con Napoleón y las finanzas novohispanas, 1803-1808. Revista A (Universidad Autónoma Metropolitana-Azcapotzalco), 9(27), 41-54.

MARICHAL, C. (otoño, 1989b). La Iglesia y la crisis financiera del virreinato, 1780-1808: apuntes sobre un tema viejo y nuevo. Relaciones. Estudios de Historia y Sociedad, 40, 103-129.

MARICHAL, C. (1990). Las guerras imperiales y los préstamos novohispanos, 1781-1804. Historia Mexicana, 39(4), 881-907.

MARICHAL, C. (1992). La bancarrota del virreinato: finanzas, guerra y política en la Nueva España, 1770-1808 (pp. 153-186). En J. Z. VÁZQUEZ (coord.), Interpretaciones del siglo XVIII mexicano. El impacto de las reformas borbónicas (pp. 153-186). México: Editorial Nueva Era.

MARICHAL, C. (1995). La Iglesia y la corona: la bancarrota del gobierno de Carlos IV y la consolidación de vales reales en la Nueva España (pp. 241-261). En M. P. MarTínez (coord.), Iglesia, Estado y economía. Siglos XVI al XIX. (pp. 241-261) México, Universidad Nacional Autónoma de México/Instituto de Investigaciones Dr. José María Luis Mora.

MARICHAL, C. (1999). La bancarrota del virreinato. Nueva España y las finanzas del Imperio español, 1780-1810. México: Fondo de Cultura Económica/El Colegio de México. 
MARICHAL, C. (2007). Bankruptcy of empire. Mexican silver and the wars between Spain, Britain and France, 1760-1810. Cambridge: Cambridge University Press.

Méndez, J. R. (2012). La quiebra del Tribunal de Minería de Nueva España vista mediante el financiamiento a las actividades bélicas de la corona española, y su herencia a la deuda pública mexicana. Revista Mexicana de Historia del Derecho, 26, 25-68.

Ortiz, J. (1997). Guerra y gobierno: los pueblos y la independencia de México. Sevilla: Universidad Internacional de Andalucía.

SÁNCHEZ, E. (2012). Los impactos fiscales de una guerra distante: crisis y restauración de la Real Hacienda en la provincia de Yucatán (1801-1821). Revista de Historia Económica, 30(3), 323-352.

SÁNCHEZ, E. (2013a). Corte de caja. La Real Hacienda de Nueva España y el primer reformismo fiscal de los Borbones (1720-1755). Alcances y contradicciones. México: Instituto de Investigaciones Dr. José María Luis Mora.

SÁNCHEZ, E. (2013b). Los mecanismos de financiamiento de la contrainsurgencia, 18101821 (pp. 95-122). En L. LudLOW (coord.), El sustento económico de las revoluciones en México (pp. 95-122). México: Universidad Nacional Autónoma de México.

SÁnchez, E. (2014a). Antonio de Medina y Miranda (1771-1821): la deuda pública y la paráfrasis de Adam Smith (pp. 73-92). En E. SÁnchez (coord.), Pensar la Hacienda pública. Personajes, proyectos y contextos en torno al pensamiento fiscal en Nueva España y México (siglos XVIII-XX) (pp. 73-92). México: Instituto de Investigaciones Dr. José María Luis Mora.

SÁnchEZ, E. (2014b). Economía y fiscalidad en la guerra de Independencia. Nueva España (1810-18121) (pp. 163-224). En J. Gelman, E. Llopis y C. Marichal (coords.), Iberoamérica y España antes de las independencias, 1700-1820. Crecimiento, reforma y crisis (pp. 163-224). México: Instituto de Investigaciones Dr. José María Luis Mora/El Colegio de México.

SÁnchEz, E. (2015). Los egresos de la Real Hacienda de Nueva España durante el siglo XVIII: estructura, dinámica y contradicciones. En E. SÁnCHEZ (coord.), El gasto público en los Imperios ibéricos. Siglo XVIII. México: Instituto de Investigaciones Dr. José María Luis Mora.

Stasavage, D. (2003). Public debt and the birth of the democratic state: France and Great Britain, 1688-1789. Nueva York: Cambridge University Press.

Sugawara, M. (1967). Los antecedentes coloniales de la deuda pública de México. Parte 1. España: Los vales reales, orígenes y desarrollo de 1780 a 1804. Boletín del Archivo General de la Nación. Segunda serie, t. VIII, 1-2, 129-402.

Sugawara, M. (1976). La deuda pública de España y la economía novohispana, 1804-1809. México: Instituto Nacional de Antropología e Historia.

Tenenbaum, B. A. (1985). México en la época de los agiotistas, 1821-1857. México: Fondo de Cultura Económica.

TePaske, J. J. (1989). The financial disintegration of the royal government of Mexico during the epoch of independence (pp. 63-83). En J. Rodríguez (comp.), The 
independence of Mexico and the creation of the new nation (pp. 63-83). Los Ángeles: University of California.

TePAske, J. J. (enero-abril 1991). La crisis financiera del virreinato de Nueva España a fines de la colonia. Secuencia. Revista de Historia y Ciencias Sociales, 19, 123-140.

TORRes, R. (2013). El precio de la guerra. El Estado fiscal-militar de Carlos III (1778-1783). Madrid: Marcial Pons.

VALLE, G. DEL (1995). Las corporaciones religiosas en los empréstitos negociados por el Consulado de México a fines del siglo XVIII (pp. 225-239). En M. P. MarTínez (coord.), Iglesia, Estado y economía. Siglos XVI al XIX. México: Universidad Nacional Autónoma de México/Instituto de Investigaciones Dr. José María Luis Mora.

VALLE, G. DEL (julio-diciembre, 1996). Historiografía y fuentes sobre la deuda interna novohispana. América Latina en la Historia Económica, 6, 33-39.

VAlle, G. DEL (1997). El Consulado de Comerciantes de la ciudad de México y las finanzas novohispanas, 1592-1827 (Tesis de doctorado en Historia). México, El Colegio de México.

VAlle, G. DEL (2001). El Consulado de México en la financiación de la guerra contra los insurgentes, 1811-1817 (pp. 203-222). En E. SÁNCHEZ, L. JÁUREGui y A. IbARRA (coords.), Finanzas y politica en el mundo iberoamericano. Del antiguo régimen a las naciones independientes (pp. 203-222). México: Universidad Autónoma del Estado de México/Instituto de Investigaciones Dr. José María Luis Mora/Universidad Nacional Autónoma de México.

VAlle, G. DEL (2012). Finanzas piadosas y redes de negocios. Los mercaderes de la ciudad de México ante la crisis de Nueva España, 1804-1808. México: Instituto de Investigaciones Dr. José María Luis Mora.

VAlle, G. DEL (2013). Financiamiento de los mercaderes de México para la lucha contra la invasión napoleónica en España y la contrainsurgencia (pp. 67-93). En L. LudLOW (coord.), El sustento económico de las revoluciones en México. México: Universidad Nacional Autónoma de México.

VegA, J. (1990). Los primeros préstamos de la guerra de independencia, 1809-1812. Historia Mexicana, 156, 909-931.

Wobeser, G. VON (2002). Gestación y contenido del real decreto de consolidación de vales reales para América. Historia Mexicana, 51(4), 787-827.

Wobeser, G. VON (2003). Dominación colonial. La consolidación de vales reales, 1804-1812. México: Universidad Nacional Autónoma de México.

Wobeser, G. vON (2006). La consolidación de vales reales como factor determinante de la lucha de independencia en México, 1804-1808. Historia Mexicana, 56(2), 373- 425. 


\section{OTRAS FUENTES}

\section{Archivos}

Biblioteca Nacional, Madrid, España.

Archivo General de la Nación, Ciudad de México, México.

Archivo General de Indias, Sevilla, España.

\section{Bibliografía}

TePaske, J. J. y Klein, H. S. (1986-1988). Ingresos y egresos de la Real Hacienda de Nueva España (2 vols.). México: Instituto Nacional de Antropología e Historia. 